Disponível em:

http://editora.unoesc.edu.br/index.php/race

RACE, Joaçaba, v. 17, n. 1, p. 151-174, jan./abr. 2018

\title{
COMPETÊNCIAS EXIGIDAS NOS PRIMEIROS ANOS DA CARREIRA DE AUDITORIA EM UMA BIG FOUR
}

Competences required in the first years of the audit career in a Big Four

Gabriel Nilson Coelho

E-mail: gn.coelho@hotmail.com

Mestrando em Contabilidade na Universidade Federal de Santa Catarina; Graduado em Administração Empresarial pela Universidade do Estado de Santa Catarina; Graduado em Ciências Contábeis pela Universidade Federal de Santa Catarina.

Chefe Financeiro do Departamento de Contabilidade e Finanças da Universidade

Federal de Santa Catarina.

Endereço para contato: Avenida Desembargador Vitor Lima, n. 222, Prédio II da Reitoria, $6^{\circ}$ andar, sala 602, Trindade, 88040-400, Florianópolis, Santa Catarina, Brasil.

\section{Rita de Cássia Correa Pepinelli Camargo}

E-mail: ritapepinelli@hotmail.com

Mestre e Doutoranda em Contabilidade pela Universidade Federal de Santa Catarina.

Marcelo Haendchen Dutra

E-mail: marcelufsc45@gmail.com

Doutor em Engenharia de Produção pela Universidade Federal de Santa Catarina;

Mestre em Contabilidade pela Universidade Federal de Santa Catarina;

Professor Adjunto vinculado ao Departamento de Contabilidade da Universidade

Federal de Santa Catarina.

Sérgio Murilo Petri

E-mail: smpetri@gmail.com

Doutor e Mestre em Engenharia de Produção pela Universidade Federal de Santa Catarina; Professor Adjunto e do Programa de Mestrado em Contabilidade na Universidade Federal de Santa Catarina. 
Resumo

Neste estudo teve-se como objetivo identificar as competências necessárias na percepção do profissional de auditoria para a execução do trabalho nos primeiros anos de carreira em uma firma de auditoria. Para investigar as competências exigidas do profissional de auditoria nos primeiros anos de carreira, o procedimento técnico selecionado foi o survey/levantamento, e a amostra do estudo foi composta por profissionais que trabalham em uma firma de auditoria Big Four. Foram enviados 62 questionários e obtidas 41 respostas, representando uma taxa de retorno de 66,12\%. Entre as competências utilizadas no questionário, 13 foram extraídas do estudo de Cardoso (2006) e mais seis do estudo de Camargo (2012). A análise dos dados foi realizada por meio de estatísticas descritivas como percentuais e médias. Além da estatística descritiva, foi empregado também um teste não paramétrico (Teste U de Mann-Whitney) para a diferença de média. Os resultados demonstraram que das competências analisadas o conhecimento de "Contabilidade e Finanças", “Atualização Profissional”, "Integridade e Confiança”, “Atendimento”, “Comunicação”, “Ouvir eficazmente” e "Trabalho em equipe” apresentaram média acima de quatro (escala Likert de cinco pontos). Entre estas, as competências "Trabalho em Equipe” " “Atendimento” demonstraram que os iniciantes na carreira têm suas habilidades interpessoais exigidas, seja com os companheiros de trabalho, seja com os clientes auditados. Considera-se que a contribuição do estudo reside no fato de identificar empiricamente as competências exigidas dos profissionais de auditoria nos anos iniciais da carreira, o que pode servir como base para estudantes que pretendam seguir a profissão.

Palavras-chave: Auditoria. Competência. Perfil profissional.

\section{Abstract}

The objective of this study is to identify the necessary skills in the perception of the audit professional for the execution of the work in the first years of the professional career. In order to investigate the required competencies of the audit professional in the first years of the career, the selected technical procedure was the survey, and the sample of the study was composed by professionals working in a Big Four audit firm. A total of 62 questionnaires were sent and 41 responses were obtained, representing a rate of return of $66.12 \%$. Among the skills used in the questionnaire, thirteen were extracted from the study by Cardoso (2006) and six from Camargo's study (2012). Data analysis was performed using descriptive statistics such as percentages and averages. In addition to the descriptive statistics, a non-parametric test (Mann-Whitney U test) was used for mean difference. The results showed that, from the skills analyzed, the knowledge of "Accounting and Finance", "Professional Update", "Integrity and Confidence", "Attendance", "Communication”, "Listen effectively" and "Teamwork", four (Likert five-point scale). Among these, the "Teamwork" and "Attendance" skills demonstrate that beginners in the career have their required interpersonal skills, be it with co-workers or audited clients. It is considered that the contribution of the study lies in the fact of empirically 
identifying the skills required of audit professionals in the early years of the career, which can serve as a basis for students wishing to pursue the profession.

Keywords: Audit. Competence. Professional profile.

\section{INTRODUÇÃO}

A auditoria, uma das técnicas contábeis existentes, juntamente com a escrituração, demonstração e análise de balanço, ocupa atualmente um lugar de destaque no cenário econômico, político e social. Reconhecida internacionalmente como atividade que fornece confiabilidade às informações contábeis, a auditoria vem sendo cada vez mais requisitada pelas empresas no Brasil em razão do desenvolvimento e da expansão dos mercados (ATTIE, 2011).

Ao ingressarem em uma firma de auditoria os profissionais iniciantes na carreira atuam como trainees e podem atingir diferentes posições dentro da empresa, com a possibilidade de chegarem ao topo da hierarquia, tornando-se sócios. Em cada cargo do plano de carreiras são requeridas competências distintas do profissional de auditoria, competências estas entendidas por Fleury e Fleury (2001, p. 190) como “[...] um saber agir responsável e reconhecido, que implica mobilizar, integrar, transferir conhecimentos, recursos, habilidades, que agreguem valor econômico à organização e valor social ao indivíduo.”

Pesquisas anteriores apontam a necessidade de o auditor possuir um amplo conjunto de competências que vão além das competências técnicas, como capacidade de trabalhar em equipe ou de se relacionar com ou auditados (TAN, 1999; ABDOLMOHAMMADI; SEARFOSS; SHANTEAU, 2004). Considerando a relevância da temática no campo de atuação da auditoria, neste estudo visou-se responder à seguinte questão de pesquisa: Quais são as competências requeridas dos auditores nos anos iniciais da carreira? Com o intuito de responder a essa questão, neste estudo teve-se como objetivo identificar as competências necessárias na percepção do profissional de auditoria para a execução do trabalho nos primeiros anos da carreira profissional.

Cardoso (2006) aponta a carência de estudos que tratem das competências necessárias para as especificidades da profissão contábil, entre elas a prática da auditoria. Algumas pesquisas desenvolvidas no Brasil abordam o tema, porém estão voltadas para: contadores de modo geral (CARDOSO, 2006), controllers (SILVA et al., 2010) ou auditores internos (CARMONA; PEREIRA; SANTOS, 2010). Camargo (2012) desenvolveu uma pesquisa na esfera de auditoria externa com uma abordagem voltada para o cliente de auditoria, visando investigar a percepção dos colaboradores 
das empresas auditadas sobre as competências demonstradas pelos auditores em sua atuação prática.

Não foram encontradas na literatura nacional pesquisas que abordem a percepção dos próprios auditores sobre as competências exigidas na profissão. Dessa forma, na presente pesquisa encontra-se espaço na lacuna existente sobre o tema, visto que os resultados deste estudo podem ser úteis também para os estudantes, uma vez que a decisão por uma área de atuação dentro das inúmeras possibilidades na esfera contábil é um dilema para muitos deles. Nesse caso, traçar um perfil dos profissionais atuantes no mercado profissional e verificar quais as competências exigidas no desenvolver dos trabalhos pode auxiliar os alunos que estão em dúvida acerca de qual carreira seguir após a conclusão do curso.

Este artigo está dividido em cinco seções. Além desta introdução, no próximo tópico será apresentada a revisão da literatura. Na sequência serão apresentados os procedimentos metodológicos e os resultados da pesquisa e; por fim, a conclusão do estudo e as referências.

\section{REVISÃO DA LITERATURA}

\subsection{COMPETÊNCIAS DO CONTADOR}

Fleury e Fleury (2001, p. 190) apresentam a definição de competência como “[...] um saber agir responsável e reconhecido, que implica mobilizar, integrar, transferir conhecimentos, recursos, habilidades, que agreguem valor econômico à organização e valor social ao indivíduo.” Cardoso (2006) define competência na visão de Durand (1998) apresentando as três dimensões que embasam o conceito conforme apresentado na Figura 1: 
Figura 1 - As três dimensões da Competência

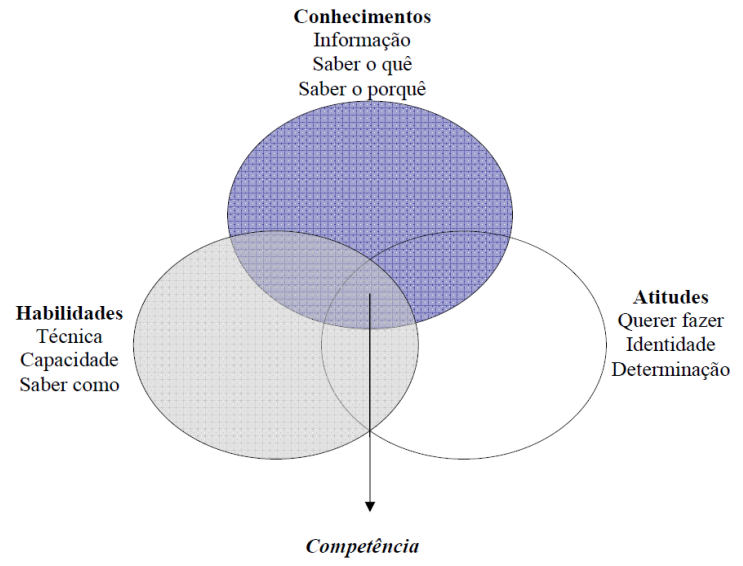

Fonte: Durand (1998 apud CARDOSO, 2006, p. 81).

Cardoso (2006) esclarece que, segundo o modelo de Durand (1998), o conhecimento se refere às informações assimiladas e já estruturadas pelo indivíduo que lhe permitem entender o mundo. A atitude está relacionada a aspectos afetivos e sociais no âmbito do trabalho, como comprometimento e motivação para atender aos resultados. A capacidade se refere à capacidade do indivíduo de absorver informações e integrá-las em um esquema preexistente, permitindo por meio da experiência e treinamentos, adquirir a habilidade que se refere ao saber fazer. A Federação Internacional de Contadores (INTERNATIONAL FEDERATION OF ACCOUNTANTS, 1998), em um dos seus "Discussion Paper”, define competência como a capacidade de executar as tarefas e funções esperadas de um contador profissional, ambos recém-formados e experientes, com o padrão esperado pelos empregadores e o público em geral.

Nesse contexto, no Brasil, Cardoso (2006) desenvolveu um modelo composto por 13 competências preponderantes para o contador. Essas competências foram divididas pelo autor em quatro fatores, conforme é apresentado no Quadro 1: 
Quadro 1 - Competências do contador

\begin{tabular}{|c|c|c|}
\hline Fator & Competências & Descrição \\
\hline $\begin{array}{l}\text { Competências Espe- } \\
\text { cíficas }\end{array}$ & $\begin{array}{l}\text { Contabilidade e finan- } \\
\text { ças, } \\
\text { Legal e } \\
\text { Ferramentas de con- } \\
\text { trole. }\end{array}$ & $\begin{array}{l}\text { Congrega as competências voltadas aos conhecimen- } \\
\text { tos específicos da área da Contabilidade, orçamento, } \\
\text { planejamento, custos e controles internos; inclui } \\
\text { competências específicas na parte da administração } \\
\text { e planejamento tributário; e inclui características } \\
\text { básicas do profissional relacionadas à sua competên- } \\
\text { cia técnica. }\end{array}$ \\
\hline $\begin{array}{l}\text { Competências de } \\
\text { Conduta e Adminis- } \\
\text { tração }\end{array}$ & $\begin{array}{l}\text { Comunicação, } \\
\text { Empreendedora, } \\
\text { Estratégica e } \\
\text { Integridade e confiança. }\end{array}$ & $\begin{array}{l}\text { Inclui competências relacionadas à visão do negócio } \\
\text { e à sua conduta perante as negociações internas e } \\
\text { externas. Abrange comunicação, análise e resolução } \\
\text { de problemas. Abrange a capacidade do contador de } \\
\text { entender o negócio da organização para poder ad- } \\
\text { ministrar todos os interesses relacionados aos dados } \\
\text { que ele procura apurar. Estão relacionadas também } \\
\text { com a postura profissional de integridade e confiança } \\
\text { necessária para o exercício de sua função. }\end{array}$ \\
\hline $\begin{array}{l}\text { Competências de } \\
\text { Técnicas de Gestão }\end{array}$ & $\begin{array}{l}\text { Gestão da informação, } \\
\text { Negociação e } \\
\text { Técnicas de gestão. }\end{array}$ & $\begin{array}{l}\text { Compreende a capacidade de gerenciar informações, } \\
\text { dada a importância da Tecnologia da Informação } \\
\text { (TI) e os sistemas de gestão integrados, conhecidos } \\
\text { como Enterprise Resource Planning (ERP). Deve-se } \\
\text { aliar esse aspecto à competência em negociação } \\
\text { de critérios para o estabelecimento de um eficiente } \\
\text { sistema de informação, passando pelo conhecimento } \\
\text { sobre técnicas de gestão utilizadas pelas organiza- } \\
\text { ções. }\end{array}$ \\
\hline $\begin{array}{l}\text { Competências de } \\
\text { Articulação }\end{array}$ & $\begin{array}{l}\text { Ouvir eficazmente, } \\
\text { Atendimento e } \\
\text { Trabalho em equipe. }\end{array}$ & $\begin{array}{l}\text { Envolve a capacidade de ouvir e atender aos diver- } \\
\text { sos usuários das informações gerenciais que o con- } \\
\text { tador administra. Toda essa exigência está vinculada } \\
\text { à capacidade de trabalhar em equipe. O modelo } \\
\text { genérico metodologicamente validado por Cardoso } \\
\text { (2006) apresenta as principais competências de um } \\
\text { contador. }\end{array}$ \\
\hline
\end{tabular}

Fonte: adaptado de Cardoso, Riccio e Albuquerque (2009, p. 372-373).

O dicionário de competências estruturado por Cardoso (2006) foi utilizado por Santos, Vasconcelos e Jesus (2011) com o objetivo de identificar a percepção dos controllers quanto às competências requeridas dos profissionais que exercem essa atividade. No estudo identificaram-se entre as competências registradas no dicionário que foram mais representativas para o cargo de controller as competências de integridade e confiança e contabilidade e finanças.

\subsection{COMPETÊNCIAS DO AUDITOR}

Gelbcke (1999 apud Pinho 2007) afirma que os atributos naturais do auditor, como independência, objetividade e habilidade para entender sistemas e controles são 
apenas argumentos básicos e o mais importante é a capacidade de aprender e estar sintonizado com as necessidades do mercado.

Esse fato ressalta a importância do aprendizado por parte dos profissionais de auditoria, buscando a atualização constante. Ao ingressar em uma firma de auditoria, o profissional passa a desenvolver competências que o habilitem a alcançar cargos e responsabilidades maiores em sua carreira. A Norma Contábil NBC PA 01 (CONSELHO FEDERAL DE CONTABILIDADE, 2009) trata da responsabilidade da firma em desenvolver as competências de seus profissionais, estipulando os métodos que podem ser utilizados para o desenvolvimento dessas competências, como educação profissional e desenvolvimento profissional contínuo, incluindo treinamento, experiência de trabalho, entre outros.

Nesse sentido, o desenvolvimento profissional do auditor estimulado por meio dos diferentes métodos existentes deve ser contínuo. Em cada cargo ocupado ao longo da carreira, o auditor necessita utilizar diferentes habilidades e competências. Nos primeiros anos de carreira as tarefas atribuídas aos iniciantes são de cunho operacional, tendo em vista a pouca experiência e conhecimento dos profissionais de auditoria. Helliar, Monk e Stevenson (2006) tratam da relação entre experiência e julgamento profissional nos primeiros anos de auditoria, indicando que o uso de julgamento é uma parte fundamental do processo de auditoria, mas requer experiência em auditoria antes de ser capaz de realizá-lo de forma eficaz, portanto, essa não é uma competência requerida nos anos iniciais da carreira do auditor.

As tarefas inerentes a um programa de auditoria são divididas entre os membros que formam a equipe de trabalho, segundo o cargo que cada um ocupa. Sá (2009, p. 77) apresenta a seguinte segregação de tarefas por nível de exigência de cultura e recursos mentais. No Grupo I - altíssimo nível: Planejamento, Pareceres, Conclusões e Interpretações; no Grupo II - alto nível: Avaliação dos Planos e Relatórios; e, por fim, no Grupo III - médio nível: Execução dos Planos. Verifica-se na segregação apresentada que a parte operacional do programa de trabalho exige um nível médio de cultura e recursos mentais, podendo, assim, ser executada por profissionais iniciantes, com a devida orientação e supervisão.

Ao buscar apresentar de forma genérica as características de cada cargo da carreira de auditoria, Jund (2001, p. 56) apresenta a seguinte descrição dos cargos iniciais:

a) Auditor Trainee ou Assistente: deve possuir tempo de experiência de zero a dois anos; ter curso superior ou em andamento; realizar função de natureza especializada, destinada a participar na execução dos trabalhos 
de auditoria, avaliando a adequação dos controles internos nos seus diversos aspectos;

b) Auditor Pleno ou Semissênior: deve ter curso superior completo e cursos de formação específica e básico de auditoria; possuir registro no Conselho Regional de Contabilidade e ter visão abrangente da atuação da auditoria. Além disso, em geral o tempo de experiência é mais abrangente, de dois a cinco anos na área. A função é de natureza especializada, destinada a acompanhar e executar os trabalhos de auditoria, avaliando a adequação dos controles internos, nos seus aspectos orçamentários, financeiros, contábeis, fiscais, tributários, administrativos e de sistemas informatizados de processamento de dados;

c) Auditor Sênior: deve possuir tempo de experiência de cinco a dez anos no ramo. Além dos requisitos do Auditor Pleno, deve ter cursos que integrem o plano básico de desenvolvimento para Auditor Sênior. A função é de natureza especializada, destinada a coordenar, acompanhar, executar e revisar os trabalhos de auditoria, de forma a assegurar a conformidade com os padrões de desempenho. O Sênior é o encarregado dos trabalhos no campo, onde irá determinar a natureza do trabalho e preparar o programa de auditoria, com base nas informações fornecidas pelo gerente de auditoria ou supervisor.

Verifica-se que ao descrever a função dos cargos, os cargos de “Trainee ou Assistente” e "Pleno ou Semissênior” recebem respectivamente a descrição de "participar na execução” e “acompanhar e executar os trabalhos”. Já para o cargo de Sênior a função descrita pelo autor é a de “coordenar, acompanhar, executar e revisar os trabalhos de auditoria”. Dessa forma, entende-se que as competências requeridas em cada função poderão ser diferentes, conforme já discutido na literatura em estudos anteriores como os de Tan e Libby (1997) e de Abdolmohammadi (2008).

Tan e Libby (1997) verificaram que as exigências requeridas de cada função na carreira de auditoria variam. Para os autores, no início da carreira, a demanda de trabalho de um Assistente é mais estruturada e de natureza técnica. Quando o profissional passa a exercer funções de Sênior, as tarefas são mais desestruturadas, exigindo além de conhecimento técnico mais avançado a habilidade de resolução de problemas. Quando o profissional chega ao nível de gerente e sócio deve deter competências relacionadas à gestão, pois entre suas tarefas está a gestão dos seus subordinados e dos clientes da firma de auditoria. 
Tan (1999) examinou as competências consideradas relevantes para um desempenho superior do auditor e a importância de mudanças dessas competências em diferentes níveis da carreira. Os resultados mostraram variações na importância relativa das competências em diferentes níveis da organização. Por exemplo, foram consideradas competências relevantes para profissionais que ocupavam funções de Assistentes o trabalho em equipe e a capacidade de saber o que é relevante. Além destas, para aqueles que ocupavam a função de Sênior também foram consideradas competências relevantes a comunicação, a resolução de problemas, o conhecimento técnico, o planejamento e a liderança. Já para profissionais que ocupavam as funções de sócios ou gerentes, competências como relacionamento interpessoal, conhecimento do cliente e perspicácia nos negócios foram destacadas.

Algumas diferenças entre as competências requeridas ao longo da carreira também foram destacadas no estudo de Tan (1999). A perspicácia nos negócios foi considerada relevante apenas nos níveis de sócio e gerente. De forma similar a visibilidade foi considerada relevante apenas para profissionais que ocupavam a função de sócio. A liderança foi considerada menos importante pelos profissionais que ocupavam a função de Assistentes em comparação aos outros níveis. Por outro lado, o trabalho em equipe foi considerado mais relevante para os profissionais que ocupavam as funções de seniores e Assistentes do que para aqueles que eram sócios.

Alberton (2002), em um levantamento realizado junto a firmas de auditoria que atuam nas regiões Sul e Sudeste do Brasil, elencou um rol de competências que o profissional deve possuir na percepção das firmas de auditoria, para que apresente um desempenho satisfatório. Entre elas estão: dinamismo e proatividade, liderança, comprometimento com resultados, criação e inovação, comunicação, empreendedorismo, trabalho em equipe, ética e independência, pensamento crítico, autoconfiança, argumentação, maturidade e responsabilidade, relacionamento interpessoal, motivação/ orientação para o desenvolvimento pessoal e profissional, resolução de problemas, conflitos e negociação, iniciativa e ambição, capacidade de lidar com pressão e flexibilidade em situações tensas, autodesenvolvimento, e lealdade.

Um dos estudos empíricos relacionados ao tema competências do auditor foi desenvolvido por Abdolmohammadi, Searfoss e Shanteau (2004). Os autores investigaram 114 auditores sócios de uma firma de auditoria integrantes na época das Big Six. Os respondentes avaliaram a importância de cada atributo em uma lista predefinida de 25 itens. Como resultado, os auditores identificaram como mais relevantes atributos referentes às características que podem ser geralmente classificadas como habilidades 
interpessoais, como liderança (por exemplo, “respeitado”), marketing (por exemplo, “foco de marketing”) e reconhecimento de autoridade.

Abdolmohammadi (2008) também encontrou diferenças na percepção de posse de competências entre auditores, considerando seu nível de experiência ou sua colocação profissional. O autor encontrou que a percepção da posse de algumas competências como conhecimento atual, solução de problemas, experiência, percepção, comunicação, autoconfiança, adaptação, capacidade de saber o que é relevante, responsabilidade, capacidade de fazer exceções, e tolerância ao estresse aumentou de acordo com a função ocupada pelo auditor.

Camargo (2012) investigou a percepção dos profissionais que tiveram contato com os profissionais de auditoria. Os resultados apontaram que a percepção dos respondentes que tiveram contato com auditores de níveis mais altos, como sócio e gerente sobre as competências investigadas, em geral, foi maior que a percepção dos respondentes que tiveram contato com auditores de níveis mais baixos, como Trainee/ Assistente, Pleno/Semissênior e Sênior/Supervisor, sugerindo que essas competências são adquiridas e melhoradas ao longo da carreira do auditor. Além disso, profissionais que tiveram contato com auditores que ocupavam a função de gerente ou sócio indicaram uma percepção mais elevada de competências como comunicação, habilidades de treinamento, relacionamento interpessoal e liderança em comparação aos que tiveram contato com auditores que ocupavam funções de níveis menos elevados, como Trainee/Assistente, Pleno/Semissênior ou Sênior/Supervisor. Outra competência ressaltada pelos respondentes que tiveram contato com sócios foi o foco no cliente. Em geral, percebe-se que os resultados apontados em estudos realizados fora do Brasil e considerando a percepção dos próprios auditores convergem com os resultados apontados por Camargo (2012), que considerou a percepção de profissionais que tiveram contato com os auditores.

Na próxima seção serão apresentados os procedimentos metodológicos adotados para a realização deste estudo.

\section{PROCEDIMENTOS METOdOLÓGICOS}

Para investigar as competências exigidas do profissional de auditoria nos primeiros anos de carreira, o procedimento técnico selecionado foi o survey/levantamento. Conforme Martins e Theóphilo (2009, p. 60), o levantamento é útil em casos “[...] que o pesquisador deseja responder a questões acerca da distribuição de uma variável ou das relações entre características de pessoas ou grupos”, nesse caso, é preciso iden- 
tificar a percepção dos profissionais de auditoria sobre as competências exigidas no decorrer dos seus trabalhos.

A amostra do estudo é composta por profissionais que trabalham em uma firma de auditoria que pertence ao grupo das Big Four e ocupam os cargos iniciais da carreira, estando no máximo em seu terceiro ano de firma. A seleção da amostra foi do tipo intencional e não probabilística.

$\mathrm{O}$ instrumento de coleta de dados foi divido em duas partes. A primeira engloba dez questões que visam traçar o perfil dos respondentes com o intuito de obter informações como sexo, faixa etária e área de formação. A segunda contempla as competências extraídas dos estudos de Cardoso (2006) e Camargo (2012), as quais o respondente deveria classificar com que frequência são exigidas no desenvolver do seu trabalho. Para a classificação das competências foi adotada uma escala do tipo Likert, em que 1 indicava "competência não exigida no decorrer dos trabalhos” e 5 "competência exigida frequentemente no decorrer dos trabalhos". O tempo médio para responder o questionário foi estimado em cinco minutos.

O questionário foi enviado aos potenciais respondentes via internet através da ferramenta Google ${ }^{\mathrm{TM}}$ Docs. Os profissionais foram abordados por e-mail e/ou através das redes sociais. Foram enviados 62 questionários e obtidas 41 respostas, representando uma taxa de retorno de 66,12\%. O acesso aos profissionais foi facilitado tendo em vista que um dos autores trabalhou cerca de três anos na firma de auditoria escolhida. Como delimitação, deve-se observar que o estudo se restringe a uma amostra de profissionais atuantes na região Sul do Brasil, em uma Big Four e estão no início da carreira (até três anos de firma). Além disso, os dados foram coletados no período de 15 de setembro a 15 de outubro de 2014.

Das competências utilizadas no questionário, 13 foram extraídas do estudo de Cardoso (2006) e mais seis do estudo de Camargo (2012). As competências extraídas deste último estudo foram as identificadas pela autora como as de maior percepção pelos respondentes que tiveram contato com profissionais classificados como Trainee/ Assistente. Foram escolhidas apenas seis competências do estudo de Camargo (2012) para não tornar o instrumento de coleta muito extenso. O Quadro 2 apresenta as competências elencadas no questionário utilizado para a coleta dos dados: 
Quadro 2 - Competências investigadas

(continua)

\begin{tabular}{|c|c|c|}
\hline Fator & $\begin{array}{l}\text { Compe- } \\
\text { tência }\end{array}$ & Descrição \\
\hline \multicolumn{3}{|c|}{ Painel A: Competências extraídas do estudo de Cardoso (2006) } \\
\hline \multirow{3}{*}{$\begin{array}{l}\text { Compe- } \\
\text { tências } \\
\text { de Arti- } \\
\text { culação }\end{array}$} & $\begin{array}{l}\text { Ouvir Efi- } \\
\text { cazmente }\end{array}$ & $\begin{array}{l}\text { Desenvolve diálogos interativos com as pessoas e pergunta por mais detalhes } \\
\text { sobre os assuntos. Avalia as mensagens e fornece feedbacks. }\end{array}$ \\
\hline & $\begin{array}{l}\text { Atendi- } \\
\text { mento }\end{array}$ & $\begin{array}{l}\text { Sabe entender e dialogar demonstrando corretamente os conceitos e critérios } \\
\text { utilizados no sistema de informação, tanto com a equipe de trabalho quanto } \\
\text { com os profissionais da empresa auditada em seus diferentes cargos. }\end{array}$ \\
\hline & $\begin{array}{l}\text { Trabalho } \\
\text { em Equipe }\end{array}$ & $\begin{array}{l}\text { Coopera com os demais membros da equipe e é comprometido com as metas } \\
\text { e objetivos da equipe. Compreende e se esforça para o bem da equipe ao } \\
\text { invés de servir a seus próprios interesses. }\end{array}$ \\
\hline \multirow{3}{*}{$\begin{array}{l}\text { Compe- } \\
\text { tências } \\
\text { de Téc- } \\
\text { nicas de } \\
\text { Gestão }\end{array}$} & $\begin{array}{l}\text { Negocia- } \\
\text { ção }\end{array}$ & $\begin{array}{l}\text { Realiza acordos com as várias áreas envolvidas com o sistema de informação } \\
\text { e mensuração de desempenho, adicionando valor e vantagens competitivas às } \\
\text { negociações. Busca opções para atender aos interesses dos envolvidos e da } \\
\text { empresa. }\end{array}$ \\
\hline & $\begin{array}{l}\text { Gestão da } \\
\text { informa- } \\
\text { ção }\end{array}$ & $\begin{array}{l}\text { Capacidade de gerenciar todas as informações necessárias para o bom anda- } \\
\text { mento dos trabalhos, interagindo com áreas correlatas, como Tecnologia de } \\
\text { Informação (TI). }\end{array}$ \\
\hline & $\begin{array}{l}\text { Técnicas } \\
\text { de Gestão }\end{array}$ & $\begin{array}{l}\text { Demonstra estar atualizado com as técnicas, dados e novos conhecimentos } \\
\text { por meio de leitura, cursos, viagens, congressos, etc. }\end{array}$ \\
\hline \multirow{3}{*}{$\begin{array}{l}\text { Compe- } \\
\text { tências } \\
\text { de Con- } \\
\text { duta e } \\
\text { Adminis- } \\
\text { tração }\end{array}$} & $\begin{array}{l}\text { Integrida- } \\
\text { de e Con- } \\
\text { fiança }\end{array}$ & $\begin{array}{l}\text { Tem integridade e exprime positivamente seus valores e crenças pessoais de } \\
\text { maneira consistente com os padrões éticos de sua empresa. Transmite con- } \\
\text { fiança pelo cumprimento dos compromissos assumidos. }\end{array}$ \\
\hline & $\begin{array}{l}\text { Comuni- } \\
\text { cação }\end{array}$ & $\begin{array}{l}\text { Estabelece sintonia nas comunicações com pessoas ou grupos, entendendo } \\
\text { mensagens e é entendido. Demonstra boa articulação, boa articulação ao } \\
\text { comunicar ideias por escrito e verbalmente. }\end{array}$ \\
\hline & $\begin{array}{l}\text { Empreen- } \\
\text { dedor }\end{array}$ & $\begin{array}{l}\text { Desenvolve soluções criativas aos problemas da empresa e dos clientes. Pro- } \\
\text { cura inovar diante das restrições da empresa. Assume riscos calculados. }\end{array}$ \\
\hline \multirow{3}{*}{$\begin{array}{l}\text { Compe- } \\
\text { tências } \\
\text { Específi- } \\
\text { cas }\end{array}$} & $\begin{array}{l}\text { Contabi- } \\
\text { lidade e } \\
\text { Finanças }\end{array}$ & $\begin{array}{l}\text { Domina e interpreta os conceitos relacionados à área de contabilidade e } \\
\text { finanças empresariais, atendendo aos interesses dos usuários internos e } \\
\text { externos dessa informação e das normas vigentes no ambiente nacional e } \\
\text { internacional. }\end{array}$ \\
\hline & $\begin{array}{l}\text { Ferra- } \\
\text { mentas de } \\
\text { Controle }\end{array}$ & $\begin{array}{l}\text { Conhece as ferramentas de controle e gestão, como orçamento, controle } \\
\text { interno, custos, fluxo de controle de caixa, entre outros. }\end{array}$ \\
\hline & Legal & $\begin{array}{l}\text { Conhece e acompanha as exigências legais e as responsabilidades inerentes } \\
\text { à profissão. }\end{array}$ \\
\hline
\end{tabular}


(conclusão)

\begin{tabular}{|c|c|c|}
\hline Fator & $\begin{array}{l}\text { Compe- } \\
\text { tência }\end{array}$ & Descrição \\
\hline \multicolumn{3}{|c|}{ Painel B: Competências extraídas do estudo de Camargo (2012) } \\
\hline \multirow{6}{*}{$\begin{array}{l}\text { Habilida- } \\
\text { des } \\
\text { pessoais }\end{array}$} & $\begin{array}{l}\text { Compor- } \\
\text { tamento } \\
\text { ético }\end{array}$ & $\begin{array}{l}\text { Apresenta atitudes pautadas pelo respeito ao próximo, integridade, senso de } \\
\text { justiça e é impessoal em suas ações. }\end{array}$ \\
\hline & Lealdade & $\begin{array}{l}\text { Demonstra sinceridade, franqueza e honestidade. É fiel aos seus compromis- } \\
\text { sos relacionados à realização dos trabalhos de auditoria. }\end{array}$ \\
\hline & Ambição & $\begin{array}{l}\text { Demonstra querer fortemente algo, colocando a mente e a vontade focadas } \\
\text { em um objetivo, fazendo de tudo para que este se concretize, porém, dentro } \\
\text { dos limites da ética. Busca } \\
\text { atingir os objetivos por seu próprio merecimento. }\end{array}$ \\
\hline & $\begin{array}{l}\text { Gestão do } \\
\text { Tempo }\end{array}$ & $\begin{array}{l}\text { Consegue gerir seu tempo de modo a cumprir todos os prazos relacionados } \\
\text { ao seu trabalho. Quando pressionado(a) pelo cumprimento de prazos, sabe } \\
\text { selecionar e dar prioridade às atividades mais relevantes. }\end{array}$ \\
\hline & $\begin{array}{l}\text { Compro- } \\
\text { meti-men- } \\
\text { to }\end{array}$ & $\begin{array}{l}\text { Disponibiliza todo o potencial em prol dos objetivos e metas de sua equipe, } \\
\text { colaborando e fornecendo suporte com total dedicação e empenho nos traba- } \\
\text { lhos de auditoria. }\end{array}$ \\
\hline & $\begin{array}{l}\text { Responsa- } \\
\text { bilida-de }\end{array}$ & $\begin{array}{l}\text { Busca cumprir suas obrigações e responsabilidades, demonstrando maturida- } \\
\text { de e consciência das suas ações. }\end{array}$ \\
\hline
\end{tabular}

Fonte: adaptado de Cardoso (2006) e Camargo (2012).

A análise dos resultados foi realizada por meio de estatísticas descritivas como percentuais e médias. Além da estatística descritiva, foi empregado também um teste não paramétrico (Teste U de Mann-Whitney) para diferença de média. Segundo Abdolmohammadi (2008), Tan (1999) e Tan e Libby (1997), competências diferentes podem ser requeridas ao longo da carreira de auditoria. Como a amostra do estudo é composta apenas por profissionais iniciantes, optou-se por dividir os respondentes em dois grupos para identificar se as médias das competências se diferenciam considerando o tempo de experiência deles. A segregação foi realizada entre respondentes com três anos ou mais de experiência e aqueles com menos de três anos. Essa divisão foi adotada, pois, em geral, é após três anos que o profissional começa a exercer funções diferentes na firma de auditoria, ocupando cargos diferentes de Trainees ou Assistentes e devendo adotar uma postura diferente nos trabalhos.

A respeito do Teste U de Mann-Whitney, conforme explica Fávero et al. (2009), esse é um dos testes não paramétricos alternativo ao teste paramétrico Teste $t$ de Student para duas amostras independentes. Os requisitos do teste, conforme os autores, é que a variável testada seja mensurada em uma escala ordinal ou quantitativa. A hipótese considerada no Teste de Mann-Whitney é a de não haver diferenças entre as médias dos grupos analisados e a hipótese alternativa considera haver diferenças entre os grupos (FÁVERO et al., 2009). 


\section{ANÁLISE DOS RESULTADOS}

Nesta seção são apresentados os resultados da pesquisa. Inicialmente é traçado um perfil dos respondentes para na sequência serem expostos os resultados decorrentes da percepção deles sobre as competências requeridas em suas atividades profissionais.

\subsection{PERFIL DOS RESPONDENTES}

Como relatado na seção anterior foram obtidas 41 respostas. Assim, dos respondentes que compõem a amostra, 24,39\% (10) são mulheres e 75,61\% (31) são homens. Destes, 46,43\% (19) têm 26 anos ou mais, 19,51\% (8) têm entre 22 e 23 anos, 19,51\% (8) entre 20 e 21 anos e 14,63\% (6) entre 24 e 25 anos. Quando indagados sobre curso de graduação que cursavam quando entraram na firma de auditoria, aproximadamente 83\% dos respondentes (34) indicaram que cursavam Ciências Contábeis, outros 12,2\% (5) Administração e apenas 4,88\% (2) Economia. Quanto à fase em que o respondente estava quando ingressou na firma de auditoria, 43,9\% (18) indicaram que estavam cursando entre a quarta e a sexta fases do curso e 24,39\% (10) se encontravam na parte final do curso, isto é, da sétima fase para frente. Outros 24,39\% (10) já estavam formados e apenas 7,32\% (3) estavam no início do curso (primeira a terceira fases).

Os respondentes também foram questionados sobre seu conhecimento de auditoria antes de ingressar na firma. Dos respondentes, 48,78\% (20) não tiveram nenhuma matéria relacionada à auditoria na graduação, contudo, 51,22\% (21) dos respondentes já haviam cursado matérias de auditoria durante o curso. Outro ponto analisado foi se os respondentes tinham experiência anterior de trabalho relacionada à auditoria. A maioria dos respondentes, 73,17\% (30) afirmaram que não tiveram contato com auditoria antes de ingressar na firma. Outros 21,95\% (9) afirmaram que a experiência obtida antes do ingresso na firma ocorreu por conta de terem trabalhado em empresas que eram auditadas por firmas de auditoria. Além disso, um respondente $(2,44 \%)$ afirmou que a experiência mais próxima que teve com auditoria foi um colega de faculdade que trabalhava com auditoria e apenas um (2,44\%) já atuou como auditor externo em outra firma de auditoria.

Os respondentes foram indagados sobre o segundo idioma estudado e o nível de especialização neste. Essa questão foi abordada pois nos processos seletivos das firmas de auditoria, principalmente as Big Four, por se tratarem de empresas multina- 
cionais, uma das características consideradas é o fato de o candidato dominar um segundo idioma. O inglês foi o idioma mais estudado pelos respondentes, 92,68\% (38). Outros 7,32\% (3) indicaram estudar o espanhol. Quanto ao nível de especialização no idioma, 41,46\% (17) afirmaram estar no nível iniciante, 36,59\% (15) se encontram no nível intermediário e apenas 21,95\% (8) estão no nível avançado.

Tendo em vista que as firmas de auditoria possuem planos de cargos e salários semelhantes e que a progressão de cargos ocorre anualmente, os respondentes foram indagados a respeito do último cargo ocupado. Verificou-se que apenas 7,32\% (3) dos respondentes ocupam ou ocuparam o cargo de Sênior C ou o cargo de Sênior B (3). Outros 31,71\% (13) indicaram que ocupam o cargo de Assistente A e 14,63\% (6) o cargo de Assistente B. A maioria dos respondentes, 39,02\% (16) indicaram ocupar o cargo de Trainee.

Quanto ao tempo de experiência, verificou-se que 41,46\% (17) dos respondentes possuem até um ano de experiência na firma, 12,2\% (5) de um a dois anos de experiência e 21,95\% (9) têm de dois a três anos de experiência. Outros 10 respondentes (24\%) possuem um tempo de experiência superior a três anos.

Dessa forma, observa-se que a amostra da pesquisa é composta por profissionais que ao ingressarem na firma de auditoria cursavam predominantemente Ciências Contábeis, estando entre a quarta e sexta fases do Curso. Além disso, a maioria não teve experiências anteriores com a realização da auditoria antes de ingressar na firma. O segundo idioma estudado pela maioria dos respondentes é o inglês. Verificou-se também a predominância entre os respondentes de profissionais que ocupam os cargos de Trainee e Assistentes e que têm até um ano de experiência.

\subsection{PERCEPÇÃO DOS AUDITORES SOBRE AS COMPETÊNCIAS}

A percepção do nível de exigências das competências investigadas na pesquisa pelos respondentes é apresentada na Tabela 1.

Conforme é possível observar na Tabela 1, as competências "Trabalho em Equipe”, “Integridade e Confiança”, “Atualização Profissional”, “Ouvir Eficazmente”, “Comunicação”, “Atendimento”, “Contabilidade e Finanças” possuem média superiores a 4, indicando, assim, um alto nível de exigência no decorrer dos trabalhos na percepção dos respondentes.

O resultado obtido pode ser mais bem-entendido se considerarmos as informações decorrentes do perfil geral dos respondentes, apontando o cargo de Trainee como último cargo ocupado pela maioria dos participantes da pesquisa e que a maio- 
ria possui até um ano de experiência profissional. As competências destacadas demonstram que nos anos iniciais as atividades desenvolvidas nos trabalhos demandam conhecimento na área contábil, bem como acerca dos procedimentos de auditoria, conforme demonstra a competência "Contabilidade e Finanças”. A alta exigência da competência “Atualização Profissional” demonstra ainda a importância da reciclagem do conhecimento e da busca por novidades na área do que no início da carreira. Percebe-se também o peso que as relações interpessoais possuem na execução dos trabalhos, seja com os companheiros da firma de auditoria, como demonstra a competência “Trabalho em Equipe”, seja com os clientes, como demonstra a competência “Atendimento”.

A palavra auditoria tem sua origem no latim e vem de audire, que significa ouvir. Tal definição está presente durante toda a carreira do auditor, inclusive nos anos iniciais, como demonstra a percepção da competência “Ouvir Eficazmente”, que conforme os respondentes tem um alto grau de exigência. A transmissão de informações durante a execução dos trabalhos também é essencial para o bom andamento deles e para a busca pela eficiência. As competências “Comunicação” e "Integridade e Confiança” demonstram que os iniciantes na carreira de auditoria devem a todo o momento buscar a comunicação e o repasse de informações íntegras e de forma confiável.

Tabela 1 - Percepção dos auditores sobre as competências do estudo de Cardoso (2006)

(continua)

Painel A: Estatística Descritiva

\begin{tabular}{lrrrrrr}
\hline \multicolumn{1}{c}{ Competências } & Respostas & Mínimo & Máximo & Média & Mediana & Moda \\
\hline Trabalho em Equipe & 41 & 3 & 5 & 4,78 & 5 & 5 \\
Integridade e Confiança & 41 & 3 & 5 & 4,49 & 5 & 5 \\
Atualização Profis- & 41 & 3 & 5 & 4,41 & 4 & 4 \\
sional & 41 & 3 & 5 & 4,39 & 4 & 5 \\
Ouvir Eficazmente & 41 & 1 & 5 & 4,34 & 5 & 5 \\
Comunicação & 41 & 3 & 5 & 4,32 & 4 & 4 \\
Atendimento & 41 & 3 & 5 & 4,17 & 4 & 4 \\
Contabilidade e Fi- & 41 & 1 & 5 & 3,59 & 3 & 3 \\
nanças & 41 & 2 & 5 & 3,59 & 3 & 3 \\
Ferramenta de Controle & 41 & 1 & 5 & 3,22 & 3 & 3 \\
Gestão de Informação & 41 & 1 & 5 & 2,83 & 3 & 2 \\
Legal & 41 & 1 & 5 & 2,51 & 2 & 1 \\
Empreendedor & 41 & 1 & 5 & 2,41 & 2 & 1 \\
Visão Estratégica & & & & & & \\
Negociação & & & & & & \\
\hline
\end{tabular}


(conclusão)

\begin{tabular}{|c|c|c|c|c|c|c|c|c|c|c|}
\hline \multicolumn{11}{|c|}{ Painel B: Frequência de Respostas por Nível de Exigência } \\
\hline \multirow{2}{*}{ Competências } & \multicolumn{10}{|c|}{ Frequência de Respostas por Nível de Exigência } \\
\hline & \multicolumn{2}{|c|}{5} & \multicolumn{2}{|c|}{4} & \multicolumn{2}{|c|}{3} & \multicolumn{2}{|c|}{2} & \multicolumn{2}{|c|}{1} \\
\hline Trabalho em Equipe & 33 & $80 \%$ & 7 & $17 \%$ & 1 & $2 \%$ & 0 & $0 \%$ & 0 & $0 \%$ \\
\hline Integridade e Confiança & 23 & $56 \%$ & 15 & $37 \%$ & 3 & $7 \%$ & 0 & $0 \%$ & 0 & $0 \%$ \\
\hline Comunicação & 21 & $51 \%$ & 15 & $37 \%$ & 4 & $10 \%$ & 0 & $0 \%$ & 1 & $2 \%$ \\
\hline Ouvir Eficazmente & 19 & $46 \%$ & 19 & $46 \%$ & 3 & $7 \%$ & 0 & $0 \%$ & 0 & $0 \%$ \\
\hline $\begin{array}{l}\text { Atualização Profis- } \\
\text { sional }\end{array}$ & 18 & $44 \%$ & 22 & $54 \%$ & 1 & $2 \%$ & 0 & $0 \%$ & 0 & $0 \%$ \\
\hline Atendimento & 16 & $39 \%$ & 22 & $54 \%$ & 3 & $7 \%$ & 0 & $0 \%$ & 0 & $0 \%$ \\
\hline $\begin{array}{l}\text { Contabilidade e Fi- } \\
\text { nanças }\end{array}$ & 14 & $34 \%$ & 20 & $49 \%$ & 7 & $17 \%$ & 0 & $0 \%$ & 0 & $0 \%$ \\
\hline Ferramenta de Controle & 13 & $32 \%$ & 7 & $17 \%$ & 14 & $34 \%$ & 5 & $12 \%$ & 2 & $5 \%$ \\
\hline Gestão de Informação & 8 & $20 \%$ & 10 & $24 \%$ & 21 & $51 \%$ & 2 & $5 \%$ & 0 & $0 \%$ \\
\hline Empreendedor & 7 & $17 \%$ & 7 & $17 \%$ & 8 & $20 \%$ & 10 & $24 \%$ & 9 & $22 \%$ \\
\hline Legal & 7 & $17 \%$ & 9 & $22 \%$ & 13 & $32 \%$ & 10 & $24 \%$ & 2 & $5 \%$ \\
\hline Negociação & 6 & $15 \%$ & 5 & $12 \%$ & 6 & $15 \%$ & 7 & $17 \%$ & 17 & $41 \%$ \\
\hline Visão Estratégica & 5 & $12 \%$ & 11 & $27 \%$ & 2 & $5 \%$ & 5 & $12 \%$ & 18 & $44 \%$ \\
\hline
\end{tabular}

Fonte: os autores.

Legenda: a Escala do tipo Likert em que 1 indica “competência não exigida no decorrer dos trabalhos” e 5 “competência exigida frequentemente no decorrer dos trabalhos”.

Em contrapartida as competências: "Empreendedor”, "Visão Estratégica” e "Negociação" possuem médias inferiores a três, ou seja, não são muito exigidas no decorrer dos trabalhos. Tal fato se justifica por tais competências não terem relação direta com o cargo de Trainee (cargo de maior predominância nos respondentes da amostra). A descrição feita por Jund (2001, p. 56) corrobora tal resultado quando apresenta as características da função de Sênior: “Auditor Sênior - A função é de natureza especializada, destinada a coordenar, acompanhar, executar e revisar os trabalhos de auditoria, de forma a assegurar a conformidade com os padrões de desempenho.” Em seus primeiros anos de carreira, a principal função do auditor iniciante é a execução dos trabalhos e não sua coordenação ou revisão, funções estas que serão desempenhadas futuramente quando o profissional alcançar cargos de liderança. A Tabela 3 evidencia melhor essa situação quando compara à relação entre a média das competências exigidas levando em consideração o tempo de experiência do profissional.

Com base na frequência demonstrada no Painel B da Tabela 1, observa-se que para as competências com média superior, a concentração das respostas está na faixa máxima de exigência, não recebendo respostas paras as faixas 1 e 2 que representam pouca ou nenhuma exigência. Apenas a competência “Comunicação” recebeu 
uma resposta na faixa 1 . Tal informação pode ser entendida como um outlier, um valor atípico na amostra, porém não trouxe prejuízos para a interpretação dos resultados. Já as maiores concentrações de repostas no nível 1 pertencem as competências com menores médias, significando que para boa parte dos respondentes as competências “Empreendedor”, "Visão Estratégica” e "Negociação” não foram exigidas nos primeiros anos de carreira.

Além das competências propostas por Cardoso (2006) em seu modelo genérico, foram investigadas outras seis competências pertencentes ao estudo de Camargo (2012), conforme explicado na seção 3. A Tabela 2 apresenta as respostas obtidas em relação a essas competências:

Tabela 2 - Percepção dos auditores sobre as competências do estudo de Camargo (2012)

\begin{tabular}{|c|c|c|c|c|c|c|c|c|c|c|}
\hline \multicolumn{11}{|c|}{ Painel A: Estatística Descritiva } \\
\hline \multirow{2}{*}{ Competências } & \multicolumn{10}{|c|}{ Estatística Descritiva } \\
\hline & Respostas & \multicolumn{2}{|c|}{ Mínimo } & \multicolumn{2}{|c|}{ Máximo } & \multicolumn{2}{|c|}{ Média } & \multicolumn{2}{|c|}{ Mediana } & \multirow{2}{*}{$\begin{array}{r}\text { Moda } \\
5\end{array}$} \\
\hline Comportamento Ético & 41 & \multicolumn{3}{|c|}{3} & 5 & \multicolumn{2}{|c|}{4,8} & \multicolumn{2}{|r|}{5} & \\
\hline Gestão do Tempo & 41 & \multicolumn{3}{|c|}{3} & 5 & \multicolumn{3}{|c|}{4,76} & 5 & 5 \\
\hline Comprometimento & 41 & \multicolumn{3}{|c|}{3} & 5 & \multicolumn{3}{|c|}{4,76} & 5 & 5 \\
\hline Responsabilidade & 41 & \multicolumn{3}{|c|}{3} & 5 & \multicolumn{3}{|c|}{4,73} & 5 & 5 \\
\hline Lealdade & 41 & \multicolumn{3}{|c|}{2} & 5 & \multicolumn{3}{|c|}{4,34} & 5 & 5 \\
\hline Ambição & 41 & \multicolumn{3}{|c|}{3} & 5 & \multicolumn{3}{|c|}{4,27} & 5 & 5 \\
\hline \multicolumn{11}{|c|}{ Painel B: Frequência de Respostas por Nível de Exigência } \\
\hline \multirow{2}{*}{ Competências } & \multicolumn{10}{|c|}{ Frequência de Respostas por Nível de Exigênciaa } \\
\hline & 5 & & \multicolumn{2}{|c|}{4} & \multicolumn{2}{|c|}{3} & \multicolumn{2}{|c|}{2} & \multicolumn{2}{|c|}{1} \\
\hline Comportamento Ético & 35 & $85 \%$ & 4 & $10 \%$ & 2 & $5 \%$ & 0 & $0 \%$ & 0 & $0 \%$ \\
\hline Lealdade & 23 & $56 \%$ & 11 & $27 \%$ & 5 & $12 \%$ & 2 & $5 \%$ & 0 & $0 \%$ \\
\hline Ambição & 22 & $54 \%$ & 8 & $20 \%$ & 11 & $27 \%$ & 0 & $0 \%$ & 0 & $0 \%$ \\
\hline Gestão do Tempo & 32 & $78 \%$ & 8 & $20 \%$ & 1 & $2 \%$ & 0 & $0 \%$ & 0 & $0 \%$ \\
\hline Comprometimento & 32 & $78 \%$ & 8 & $20 \%$ & 1 & $2 \%$ & 0 & $0 \%$ & 0 & $0 \%$ \\
\hline Responsabilidade & 32 & $78 \%$ & 7 & $17 \%$ & 2 & $5 \%$ & 0 & $0 \%$ & 0 & $0 \%$ \\
\hline
\end{tabular}

Conforme as informações contidas na Tabela 2, percebe-se que as competências possuem um alto grau de exigência na execução dos trabalhos de auditoria, tendo como menor média a competência “Ambição” (média de 4,27). O resultado fica mais evidente se observarmos a análise de Frequência, apresentada no Painel B da Tabela 2.

Todas as competências foram classificadas com nível de exigência acima de três de acordo com a escala de Likert proposta aos participantes. Tal resultado cor- 
robora os resultados de Camargo (2012) em que essas competências são exigidas e demonstradas pelos auditores nos anos iniciais da carreira.

A Tabela 3 apresenta um comparativo entre a média de cada competência exigida na percepção dos auditores segregadas pelo tempo de experiência. A segregação foi realizada entre respondentes com três anos ou mais de experiência e aqueles com menos de três anos. Essa divisão foi adotada pois, em geral, é após três anos que o profissional começa a exercer funções diferentes na firma de auditoria, ocupando cargos diferentes de Trainees ou Assistentes e passando a adotar uma postura diferente nos trabalhos. Além disso, conforme Abdolmohammadi (2008), Tan (1999) e Tan e Libby (1997), as competências variam em diferentes níveis da carreira do auditor e conforme o seu tempo de experiência.

Tabela 3 - Comparativo da percepção da competência por tempo de experiência

\begin{tabular}{|c|c|c|c|c|c|c|c|c|}
\hline \multirow{3}{*}{ Competências } & \multicolumn{8}{|c|}{ Teste de Igualdade/Diferença de Médias } \\
\hline & \multicolumn{2}{|c|}{ G1 } & \multicolumn{2}{|c|}{ G2 } & \multirow{2}{*}{ DM } & \multicolumn{3}{|c|}{ Teste U de Mann-Whitney } \\
\hline & $\mathbf{N}$ & MD & $\mathbf{N}$ & MD & & $\mathbf{U}$ & & $\mathbf{Z}$ \\
\hline Negociação & 27 & 1,70 & 14 & 3,79 & $-2,082$ & 46,0 & $-4,107$ & $* * *$ \\
\hline Visão Estratégica & 27 & 1,85 & 14 & 3,79 & $-1,934$ & 65,0 & $-3,608$ & $* * *$ \\
\hline Empreendedor & 27 & 2,33 & 14 & 3,79 & $-1,452$ & 81,5 & $-3,019$ & $* * *$ \\
\hline Ferramenta de Controle & 27 & 3,26 & 14 & 4,21 & $-0,955$ & 97,5 & $-2,620$ & $* * *$ \\
\hline Legal & 27 & 2,93 & 14 & 3,79 & $-0,860$ & 110,5 & $-2,228$ & $*$ \\
\hline Gestão de Informação & 27 & 3,33 & 14 & 4,07 & $-0,738$ & 107,5 & $-2,439$ & $* *$ \\
\hline Contabilidade e Finanças & 27 & 3,96 & 14 & 4,57 & $-0,608$ & 98,5 & $-2,715$ & $* * *$ \\
\hline Ambição & 27 & 4,11 & 14 & 4,57 & $-0,460$ & 135,0 & $-1,640$ & \\
\hline Integridade e Confiança & 27 & 4,41 & 14 & 4,64 & $-0,235$ & 148,0 & $-1,281$ & \\
\hline Atendimento & 27 & 4,26 & 14 & 4,43 & $-0,169$ & 153,0 & $-1,116$ & \\
\hline Comunicação & 27 & 4,30 & 14 & 4,43 & $-0,132$ & 142,5 & $-1,415$ & \\
\hline Atualização Profissional & 27 & 4,37 & 14 & 4,50 & $-0,130$ & 159,5 & $-0,930$ & \\
\hline Responsabilidade & 27 & 4,70 & 14 & 4,79 & $-0,082$ & 169,5 & $-0,744$ & \\
\hline Gestão do Tempo & 27 & 4,74 & 14 & 4,79 & $-0,045$ & 170,5 & $-0,707$ & \\
\hline Comprometimento & 27 & 4,74 & 14 & 4,79 & $-0,045$ & 170,5 & $-0,707$ & \\
\hline Ouvir Eficazmente & 27 & 4,41 & 14 & 4,36 & 0,050 & 188,0 & $-0,031$ & \\
\hline Trabalho em Equipe & 27 & 4,81 & 14 & 4,71 & 0,101 & 181,0 & $-0,320$ & \\
\hline Lealdade & 27 & 4,41 & 14 & 4,21 & 0,193 & 187,0 & $-0,061$ & \\
\hline Comportamento Ético & 27 & 4,89 & 14 & 4,64 & 0,246 & 166,5 & $-1,007$ & \\
\hline
\end{tabular}

Fonte: os autores.

Legenda: G1=Profissionais com experiência menor que 3 anos; G2=Profissionais com experiência igual ou maior que 3 anos; N=Número de Respondentes; MD=Média; DM=Diferença de Média.

Nota: ***, ** estatisticamente significantes aos níveis de $\mathrm{p}<0,01$ e $\mathrm{p}<0,05$ (bicaudal), respectivamente. 
Conforme é possível observar na Tabela 3, as competências com maior divergência são: Negociação, Visão Estratégica e Empreendedor. Tais competências apresentam uma média menor de exigência nos anos iniciais da carreira, visto que os cargos de Trainee e Assistente (A e B) são cargos de execução, já os cargos de Sênior demandam a coordenação da equipe de trabalho e um maior relacionamento com o auditado. Um fato positivo a se destacar é que em ambos os níveis de experiência as competências "Integridade e Confiança” e “Atendimento” apresentam médias altas de exigência e quase nenhuma diferença ao longo da carreira, demonstrando, assim, a importância do comportamento íntegro e da impessoalidade nas ações dos auditores ao longo da carreira, bem como a importância de saber atender e dialogar demonstrando corretamente os conceitos inerentes à profissão.

\section{CONCLUSÃO}

O objetivo com esta pesquisa foi identificar as competências necessárias na percepção do profissional de auditoria para a execução do trabalho nos primeiros anos da carreira profissional. Para atingir esse objetivo foi realizado um survey com profissionais de uma das firmas de auditoria Big Four. Das competências analisadas, o conhecimento de "Contabilidade e Finanças”, “Atualização Profissional”, “Integridade e Confiança”, “Atendimento”, “Comunicação”, “Ouvir eficazmente” e “Trabalho em Equipe” apresentaram média acima de quatro (em uma escala Likert de cinco pontos), representando um nível de exigência frequente nos trabalhos de auditoria. Entre estas, as competências “Trabalho em Equipe” e “Atendimento” demonstram que os iniciantes na carreira têm suas habilidades interpessoais exigidas, seja com os companheiros de trabalho, seja com os clientes auditados. A competência "Contabilidade e Finanças” demonstra que o profissional, mesmo na fase inicial, deve dominar e interpretar os conceitos relacionados à área de contabilidade e finanças empresariais, e, além disso, estar atualizado com as técnicas, dados e novos conhecimentos por meio de leitura, cursos, viagens e congressos, conforme demonstra a percepção da competência “Atualização Profissional”.

Além disso, a percepção da competência “Ouvir Eficazmente” demonstra que o profissional deve desenvolver diálogos interativos com as pessoas, perguntando sempre por mais detalhes sobre os assuntos tratados, avaliando as mensagens e fornecendo feedback.

A competência “Comunicação” demonstra a importância de os iniciantes na carreira de auditora saberem demonstrar boa articulação ao comunicarem ideias por 
escrito e verbalmente. Ter integridade e demonstrar positivamente seus valores e crenças pessoais de maneira consistente com os padrões éticos de sua empresa dentro do ramo da auditoria são atribuições valorizadas e exigidas dos profissionais, conforme a percepção da competência "Integridade e Confiança”.

Em contraponto, as competências "Empreendedor”, "Visão Estratégica” e "Negociação" apresentaram médias de percepção inferiores a três, ou seja, não são muito exigidas no decorrer dos trabalhos nos anos iniciais na percepção do grupo investigado. Ao cruzar as informações tempo de experiência (mais de três anos e menos de três anos) e a média das competências de cada grupo, notou-se uma maior divergência nessas três competências. Estas apresentam uma média menor de exigência nos anos iniciais da carreira, visto que os cargos de Trainee e Assistente (A e B) são cargos de execução, já os cargos de Sênior demandam a coordenação da equipe de trabalho e um maior relacionamento com o auditado. As competências "Comportamento Ético”, “Gestão do Tempo”, “Comprometimento”, “Responsabilidade”, “Lealdade e Ambição” também se demonstraram exigidas frequentemente na execução dos trabalhos de auditoria.

Considera-se que a contribuição do estudo reside no fato de identificar empiricamente as competências exigidas dos profissionais de auditoria nos anos iniciais da carreira, o que pode servir como base para estudantes que pretendam seguir a profissão. Deve-se considerar que os resultados são limitados à amostra utilizada na pesquisa, que por se tratar de uma amostra intencional pode não refletir a realidade dos demais profissionais e de outras firmas de auditoria não investigados. Além disso, o perfil dos respondentes indica pouca experiência (até três anos de carreira) e as competências consideradas importantes para eles podem não refletir as competências que seriam relevantes para profissionais com maior experiência. Assim, futuras pesquisas poderiam ampliar a amostra desta pesquisa, buscando profissionais de outras firmas de auditoria e regiões. Além disso, futuros estudos poderiam verificar as competências em outros níveis de carreira (Sênior, Gerente, Sócio) e comparar competências exigidas nas Big Four e não Big Four. Ademais, para futuros trabalhos se sugere também uma análise a partir de uma perspectiva teórica, além da relevância prática.

\section{REFERÊNCIAS}

ABDOLMOHAMMADI, M. J. Auditors' self-other agreement on perceived possession of expert attributes. In: ARNOLD, V. et al. (Ed.) Advances in Accounting Behavioral Research. England: Emerald Group Publishing Limited, 2008. v. 11. 
ABDOLMOHAMMADI, M. J.; SEARFOSS, D. G; SHANTEAU, J. An investigation of the attributes of top industry audit specialists. Behavioral Research in Accounting, v. 16, i. 1, p. 1-17, 2004.

\section{ALBERTON, L. Uma contribuição para a formação de auditores contábeis in-} dependentes na perspectiva comportamental. 2002. 272 p. Tese (Doutorado em Engenharia de Produção)-Universidade Federal de Santa Catarina, Florianópolis, 2002.

ATTIE, W. Auditoria: conceitos e aplicações. 6. ed. São Paulo: Atlas, 2011.

CAMARGO, R. C. C. P. Competências do Auditor: Um estudo empírico sobre a percepção dos auditados das empresas registradas na CVM. 2012. 194 p. Dissertação (Mestrado em Contabilidade)-Universidade Federal de Santa Catarina, Florianópolis, 2012.

CARDOSO, R. L. Competências do contador: um estudo empírico. 2006. 151 p. Tese (Doutorado em Controladoria e Contabilidade)-Universidade de São Paulo, São Paulo, 2006. Disponível em: <http://www.teses.usp.br/teses/disponiveis/12/12136/tde-03042007-100732/>. Acesso em: 29 jun. 2013.

CARDOSO, R. L.; RICCIO, E. L.; ALBUQUERQUE, L. G. Competências do contador: um estudo sobre a existência de uma estrutura de interdependência. R. Adm., São Paulo, v. 44, n. 4, p. 365-379, out./dez. 2009.

CARMONA, E.; PEREIRA, A. C.; SANTOS, M. R. A lei Sarbanes-Oxley e a percepção dos gestores sobre as competências do auditor interno. Gestão \& Regionalidade, v. 26, n. 76, p. 63-74, jan./abr. 2010.

CONSELHO FEDERAL DE CONTABILIDADE. Resolução CFC n. 1.201, de 27 de novembro de 2009. Aprova a NBC PA 01 - Controle de Qualidade para Firmas (Pessoas Jurídicas e Físicas) de Auditores Independentes. Disponível em: <http:// www.cfc.org.br>. Acesso em: 27 jun. 2013.

FÁVERO, L. P. et al. Análise de dados: Modelagem multivariada para tomada de decisões. Rio de Janeiro: Elsevier, 2009.

FLEURY, A.; FLEURY, M. T. L. Construindo o conceito de competência. Revista de Administração Contemporânea, São Paulo, p. 187, 2001. Edição Especial. 
HELLIAR, C.; MONK, E.; STEVENSON; L. The skill-set of trainee auditors. Presented at the National Auditing Conference University of Manchester. 2006. Disponível em: <http://static.aston.ac.uk/asig/Helliar.pdf>. Acesso em: 18 jun. 2013.

INTERNATIONAL FEDERATION OF ACCOUNTANTS, EDUCATION COMMITTEE. Competence-Based Approaches to The Professional Preparation of Accountants. New York, 1998. Disponível em: <http://www.ifac.org>. Acesso em: 24 jun. 2013.

JUND, S. Auditoria: conceitos, normas, técnicas e procedimentos. Rio de Janeiro: Impetus, 2001.

MARTINS, G. A.; THEÓPHILO, C. R. Metodologia da investigação científica para ciências sociais aplicadas. 2. ed. São Paulo: Atlas, 2009.

PINHO, R. C. S. Fundamentos de auditoria: auditoria contábil. Outras aplicações de auditoria. São Paulo: Atlas, 2007.

RICHARDSON, R. J. Pesquisa social: métodos e técnicas. 3. ed. São Paulo: Atlas, 1999.

SÁ, A. L. de. Curso de Auditoria. 10. ed. São Paulo: Atlas, 2009.

SANTOS, R. C. G.; VASCONCELOS, M. C. R. L.; JESUS, P. H. S. Contador Controller: Análise da percepção dos controllers quanto às competências exigidas para o desempenho da função. Parlatorium: Revista Eletrônica da FAMINAS, Belo Horizonte, p. 56-72, dez. 2011. Semestral. Disponível em: <http://www.faminasbh.edu. br/parlatorium/baixar.php?id=401>. Acesso em: 02 jul. 2013.

TAN, H. T.; LIBBY, R. Tacit managerial versus technical knowledge as determinants of audit expertise in the field. Journal of Accounting Research, v. 35, i. 1, p. 97113, 1997.

TAN, H. T. Organizational levels and perceived importance of attributes for superior audit performance. Abacus, v. 35, i. 1, p. 77-90, 1999. 


\section{Como citar este artigo:}

\section{ABNT}

COELHO, Gabriel Nilson et al. Competências exigidas nos primeiros anos da carreira de auditoria em uma Big Four. RACE, Revista de Administração, Contabilidade e Economia, Joaçaba: Ed. Unoesc, v. 17, n. 1, p. 151-174, jan./abr. 2018. Disponível em: <http://editora.unoesc.edu.br/index.php/race>. Acesso em: dia/mês/ano.

\section{APA}

Coelho, G. N., Camargo, R. de C. C. P., Dutra, M. H., \& Petri, S. M. (2018). Competências exigidas nos primeiros anos da carreira de auditoria em uma Big Four. RACE, Revista de Administração, Contabilidade e Economia, 17(1), 151-174. Recuperado em dia/mês/ano, de http://editora.unoesc.edu.br/index.php/race 